\title{
Environmental impacts of electricity generation at global, regional and national scales in 1980-2011: What can we learn for future energy planning?
}

\author{
Laurent, Alexis; Espinosa Martinez, Nieves
}

Published in:

Energy \& Environmental Science

Link to article, DOI:

$10.1039 / \mathrm{c} 4 \mathrm{ee} 03832 \mathrm{k}$

Publication date:

2015

Document Version

Peer reviewed version

Link back to DTU Orbit

Citation (APA):

Laurent, A., \& Espinosa Martinez, N. (2015). Environmental impacts of electricity generation at global, regional and national scales in 1980-2011: What can we learn for future energy planning? Energy \& Environmental Science, 8, 689-701. https://doi.org/10.1039/c4ee03832k

\section{General rights}

Copyright and moral rights for the publications made accessible in the public portal are retained by the authors and/or other copyright owners and it is a condition of accessing publications that users recognise and abide by the legal requirements associated with these rights.

- Users may download and print one copy of any publication from the public portal for the purpose of private study or research.

- You may not further distribute the material or use it for any profit-making activity or commercial gain

- You may freely distribute the URL identifying the publication in the public portal 


\title{
Environmental impacts of electricity generation at global,
}

\section{regional and national scales in 1980-2011: What can we}

\section{learn for future energy planning?}

\author{
Alexis Laurent ${ }^{1, *}$, Nieves Espinosa ${ }^{2}$ \\ ${ }^{1}$ Division for Quantitative Sustainability Assessment (QSA), Department of Management \\ Engineering, Technical University of Denmark (DTU), Produktionstorvet 424, 2800 Kgs. Lyngby,
}

Denmark

${ }^{2}$ Department of Energy Conversion and Storage, Technical University of Denmark (DTU),

Frederiksborgvej 399, Building 111, 4000 Roskilde, Denmark

* To whom correspondence should be addressed; e-mail: alau@dtu.dk, Tel.: (+45) 45254423

\begin{abstract}
The generation of electricity has been known to cause important damages to ecosystems and human health. The recognition of the global challenges posed by climate change and energy security has guided several countries to change their electricity policies over the past decades. However, have such changes entailed reduced or increased environmental impacts? Are there any identifiable patterns that could serve for steering future energy planning? To address these questions, we applied life cycle assessment to quantify a whole spectrum of environmental impacts caused by electricity generation in 199 countries for the period 1980-2011, with national differentiation of energy sources and, wherever possible, technology efficiencies. The results show that (i) environmental impact burden-shifting has occurred in the past for several countries as a result of national policies, (ii) all environmental impacts have globally increased since 1980 but with faster increase rates over the last decade, and (iii) important variations exist in the impact trends across countries and across impact categories. Our findings therefore demonstrate the need for integrating quantitative assessments of all relevant environmental impacts associated with foreseen energy systems when identifying the most sustainable energy pathways. We provide recommendations on the use of life cycle assessment for such purposes with a strong focus on application at country level so that it can directly support national energy policy-making.
\end{abstract}


Laurent A., Espinosa N., 2015. Environmental impacts of electricity generation at global, regional and national scales in 1980-2011: What can we learn for future energy planning? Energy and Environmental Science 8, 689-701. DOI: 10.1039/c4ee03832k

\section{Introduction}

Current worldwide electricity generation is largely relying on the use of fossil fuels. These energy carriers however pose significant environmental problems, in particular their climate change footprint. ${ }^{1}$ Since the United Nations Framework Convention on Climate Change and the Parties' engagements in greenhouse gas reductions taken under the subsequent Kyoto Protocol ${ }^{2}$, political incentives have thus increasingly emerged to move towards utilizing low-carbon, renewable energy sources. In the electricity sector, this has resulted in a growing number of countries establishing targets for the share of renewable energy sources, e.g. wind power or solar power, in their electricity mix (e.g. phase-out of fossils in Denmark by 2050; ${ }^{3}$ EU Climate Plan $^{4}$ targeting $20 \%$ of renewables by 2020 and $27 \%$ by 2030).

To assess the environmental impacts of electricity systems and evaluate the potential benefits brought by the switch to renewables, one approach is the use of life cycle assessment (LCA). ${ }^{5,6}$ LCA is a decision-support tool that enables to quantify environmental impacts of a product, technology or system in a life cycle perspective, i.e. from the extraction of the raw materials through their manufacture and use or operations up to their end-of-life. ${ }^{5,7}$ When performing an LCA of a system, the resource consumptions and pollutant emissions from that system life cycle are inventoried and translated into impact indicator scores using substance-specific characterisation factors embedded in life cycle impact assessment (LCIA) methods.

Several LCA studies have been conducted on electricity generation systems, from assessing single energy sources and technologies, such as coal-based power plants, ${ }^{8}$ wind power, ${ }^{9-13}$ or solar power, ${ }^{14-18}$ through evaluating and comparing groups of technologies or energy sources taking an energy output basis, ${ }^{5,19-21}$ to assessing specific systems in a local or regional context (e.g. Roth et al. $^{22}$ focusing on a large utility company in Switzerland; Lund et al. ${ }^{23}$ studying the electricity supply in Denmark with a modelling of the related market mechanisms). To the authors' knowledge, only one study recently published by Hertwich et al. has undertaken a wider perspective and assessed a number of environmental impacts, in this case from future electricity supply scenarios, at global scale, thus demonstrating global environmental benefits of low-carbon technologies. ${ }^{24}$

Three major observations can be outlined from these studies. First, the inclusion of projections or different time frames in the LCA studies, as performed in few studies (e.g. Refs. 20, 22-24), is a key aspect as the energy systems are strongly defined by international and/or national policies, in which it is often a necessary condition to ensure long-term environmental benefits. Second, as noted by Treyer et al. ${ }^{20}$, a sheer amount of studies have solely focused on greenhouse gas accountings with disregard for other environmental problems like the impacts of chemical pollution and particulate matters on human health and ecosystems. This pattern is alarming as studies focusing on climate change alone might bring the risks of suboptimisation or environmental burden shifting, i.e. when policies target reduction of specific impacts, e.g. climate change, while inadvertently increasing others. ${ }^{25}$ Finally, a third observation points out that nearly all the LCA studies have had a focus on specific technologies or on specific contexts (e.g. a given utility company as in Roth et al. ${ }^{22}$ ). Such a focus is important for product and technology development, for which the main objective is to minimise environmental impacts as early as possible in the development phase. However, in a global context, where several international and national policies attempt to define strategic energy plans that address environmental sustainability, it is necessary to adopt an overarching perspective 
that enables to comprehend the energy systems at a scale matching the reach of these energy policies, i.e. typically at regional and national scales.

In this study, we therefore conduct multi-scale retrospective assessments of a large variety of environmental impacts stemming from electricity generation to support future energy policymaking. We apply LCA to quantify these environmental impacts for each year within the period 1980-2011 at global scale as well as at regional and national scales. To our knowledge, such a wide and differentiated scoping in geographical, time and impact coverage has not been applied in earlier studies in spite of its high relevance for energy policy-making. By analysing the time and geographical differences, we aim to identify potential trends and patterns in the environmental impacts and provide recommendations to policy-makers for an adequate integration of environmental sustainability into strategic electricity planning.

\section{Methodology}

\subsection{Country-specific electricity generation data}

Historical data on electricity generation were retrieved for 199 countries and territories - termed "countries" in the following - for each year within the period 1980-2011. The collected electricity generation data encompass the electricity consumed by the end-users as well as the electricity lost during the transport and distribution system. Electricity produced from biomass, geothermal, hydropower, nuclear, solar and tidal wave sources were retrieved from the Data Shift project ${ }^{26}$ and the World Bank database. ${ }^{27}$ To match the availability of technology-specific emission factors (see Section 2.2), electricity generation data related to specific energy sources were split according to production volumes in 2008 taken from the ecoinvent 3.01 database. ${ }^{28}$ Electricity from coal was thus differentiated between hard coal and lignite sources; electricity from hydropower was differentiated between reservoir and run-of-river sources; electricity from wind was assigned to different on-shore and off-shore wind mill types classified by their power capacity; electricity from photovoltaics was differentiated between different types of installation and power capacity. Although historical data were complete for most countries, a number of assumptions were necessary to fill in gaps in the reported electricity generation from energy sources for specific countries and years. Detailed documentation of these gap-filling procedures along with the evaluation of their impacts on the outcome of the resulting worldwide electricity mapping are available in ESI- $1 \dagger$.

\subsection{Life cycle inventories}

Life cycle inventories (LCIs) are comprehensive inventories of pollutant emissions and natural resource consumptions aggregated over the entire life cycle of the power plants, i.e. from the extraction of the raw materials necessary to the building of the plants, through the consumed resources and emissions during their operations, to their final decommission. LCIs from ecoinvent 3.01, which is currently the most comprehensive LCI database, were used in this study for the generation of high voltage electricity from hard coal, lignite, natural gas, oil, nuclear power, biomass, hydropower (4 types of hydropower plants), wind power (4 types of wind mills), solar power (16 types of photovoltaic installations). ${ }^{28-30}$ The electricity transport and distribution systems are not included in these inventories. The ecoinvent 3.01 database provides average LCIs for 
electricity generation specific to 50 countries, which in total represent ca. $83 \%$ of the global electricity production in 2008. ${ }^{29,30}$ It additionally includes unspecified LCIs representing the electricity generation from different energy sources in the "rest of the world" taken as a whole; these were used for characterising the electricity generation in all countries unspecified in the ecoinvent database. The level of disaggregation of the energy sources between the life cycle inventories and the historical electricity data was different, the former being more differentiated. To bring the historical electricity generation data to the same level as LCIs, production volumes for the year 2008 and 2009 were used. Details about the modelling of the inventories are available in ESI-1 (Supplementary Methods $\dagger$ ); potential sources of uncertainties are discussed in Section 2.4.

The LCIs are based on the electric installations in the world and the country-specific differentiation primarily depends on the generation technologies and on key country parameters (e.g. wind load hours for wind power). The data sets, i.e. inputs of infrastructure and materials, outputs of emissions and by-products, are not time-differentiated and are typically considered to be valid for several years, which is reflected by the so-called "time period" of the data sets. ${ }^{29}$ Most of the original data sets have been collected in the $90 \mathrm{~s}$ and $2000 \mathrm{~s},{ }^{28}$ and, although extrapolations have been made to make them valid at present time, the time period is still expected to include the 2000s and most of the 1990s for most of the data sets. Given the long lifetimes of power plants, the inconsistencies that may arise in the assessment of the 1980s and the beginning of the 1990s are assumed to be of minor influence on the results and interpretation of this study (see also Section 2.4).

\subsection{Environmental impact assessment}

The product of the global, regional or national electricity data disaggregated per energy sources (Section 2.1) with the life cycle inventories of the technologies associated with the electricity generated from these energy sources (Section 2.2) results in total pollutant emissions and resource consumptions. These are translated into potential impact indicator scores by use of life cycle impact assessment (LCIA) methods. The LCIA methods were selected following the International Reference Life Cycle Data System (ILCD) recommended best practice for the characterisation step in LCIA. ${ }^{31,32}$ LCIA methods can be defined at "midpoint" or "endpoint" level, according to their coverage of the cause-effect chain. Endpoint methods consider the entire impact pathway from the emissions of substances to their damages on ecosystems quality, human health and natural resources, whereas midpoint methods define their indicators at some intermediary point along the cause-effect chain. The farther the impact pathway is covered, the higher the modelling uncertainties, thus explaining the very low number of recommended LCIA methods at endpoint in the ILCD recommended best practice.", 31, 32 For this reason, only “midpoint” indicators are considered in the present study.

Although 17 commonly-assessed impact categories have been evaluated in this study, only ten are fully analysed as some of the impact indicator scores either were deemed of insufficient representativeness for the study (e.g. ionising radiation impacting ecosystems ${ }^{31}$ and water use ${ }^{33}$; see also ESI-1†) or were approximated by other impact indicators. The latter category includes impacts that correlate well with climate change indicator scores. When assessing electricity generation systems, climate change scores have been demonstrated to act as an acceptable proxy for other environmental impacts, including acidification, ground-level ozone formation and terrestrial 
eutrophication. ${ }^{25}$ The ten retained impact categories therefore include climate change, toxicity of chemicals on human health (termed 'human toxicity'), differentiated between carcinogenic effects and non-carcinogenic effects, toxicity of chemicals impacting freshwater ecosystems (termed 'freshwater ecotoxicity'), eutrophication in freshwater and marine environments, respiratory impacts caused by inorganics via formation of particulate matters (termed 'respiratory inorganics'), ionising radiation impacting human health, land use, and non-renewable resource depletion; Table 1 documents the descriptions and sources of the different LCIA methods for each of these impact categories.

Table 1. Background information on the LCIA methods considered in the study ${ }^{\text {a }}$

\begin{tabular}{|c|c|c|c|}
\hline Impact category & Indicator & Unit & References for the model \\
\hline Climate change & $\begin{array}{l}\text { Radiative forcing as global } \\
\text { warming } \\
\text { (GWP100) }\end{array}$ & kg-CO ${ }_{2} \mathrm{eq} /$ pers & $\begin{array}{l}\text { Baseline model of 100-year time horizon of } \\
\text { the } \text { IPCC }^{34}\end{array}$ \\
\hline $\begin{array}{l}\text { Freshwater } \\
\text { eutrophication }\end{array}$ & $\begin{array}{l}\text { Residence time of nutrients } \\
\text { in freshwater end } \\
\text { compartment }(\mathrm{P})\end{array}$ & kg-Peq/pers & $\begin{array}{l}\text { EUTREND model as implemented in } \\
\text { ReCiPe (Struijs et } \text { al. }^{35} \text { ) }\end{array}$ \\
\hline $\begin{array}{l}\text { Marine } \\
\text { eutrophication }\end{array}$ & $\begin{array}{l}\text { Residence time of nutrients } \\
\text { in marine end compartment } \\
(\mathrm{N})\end{array}$ & kg-Neq/pers & $\begin{array}{l}\text { EUTREND model as implemented in } \\
\text { ReCiPe (Struijs et } \text { al. }^{35} \text { ) }\end{array}$ \\
\hline $\begin{array}{l}\text { Freshwater } \\
\text { ecotoxicity }\end{array}$ & $\begin{array}{l}\text { Comparative toxic unit for } \\
\text { ecosystems (CTUe) }\end{array}$ & CTUe/pers & $\begin{array}{l}\text { USEtox model (Rosenbaum et } \text { al. }^{36} \text { and } \\
\text { Henderson et al. }{ }^{37} \text { ) }\end{array}$ \\
\hline $\begin{array}{l}\text { Human toxicity } \\
\text { (cancer effects) }\end{array}$ & $\begin{array}{l}\text { Comparative toxic unit for } \\
\text { human health (CTUh) }\end{array}$ & CTUh/pers & USEtox model (Rosenbaum et al. ${ }^{36,38}$ ) \\
\hline $\begin{array}{l}\text { Human toxicity (non- } \\
\text { cancer effects) }\end{array}$ & $\begin{array}{l}\text { Comparative toxic unit for } \\
\text { human health (CTUh) }\end{array}$ & CTUh/pers & USEtox model (Rosenbaum et al. ${ }^{36,38}$ ) \\
\hline $\begin{array}{l}\text { Ionising radiation } \\
\text { (human health) }\end{array}$ & $\begin{array}{l}\text { Human exposure efficiency } \\
\text { relative to U235 }\end{array}$ & $\mathrm{kBq}-\mathrm{U}_{235} \mathrm{eq} / \mathrm{pers}$ & $\begin{array}{l}\text { Human health effect model as developed by } \\
\text { Dreicer et al. }{ }^{39} \text { (ref. Frischknecht et al. }{ }^{40} \text { ); } \\
\text { use in, e.g., ReCiPe } 2008 \text { (Goedkoop et } \\
\text { al. }^{41} \text { ) }\end{array}$ \\
\hline $\begin{array}{l}\text { Respiratory } \\
\text { inorganics }\end{array}$ & $\begin{array}{lccc}\text { Intake fraction for fine } \\
\text { particles (PM2.5) } & & \\
\end{array}$ & $\mathrm{kg}-\mathrm{PM}_{2.5} \mathrm{eq} / \mathrm{pers}$ & $\begin{array}{l}\text { Compilation in Humbert } \\
\text { and Spadaro }^{43} \text {, and Greco et al. }{ }^{44}\end{array}$ \\
\hline Land use & $\begin{array}{l}\text { Soil organic matter (soil } \\
\text { quality) }\end{array}$ & kg-C/pers & Model by Milà i Canals et al. ${ }^{45}$ \\
\hline $\begin{array}{l}\text { Non-renewable } \\
\text { resource depletion }\end{array}$ & Scarcity (metals and fossils) & kg-Sbeq/pers & CML 2002 (Guinée et al. ${ }^{46}$; Oers et al. ${ }^{47}$ ) \\
\hline
\end{tabular}

a Table adapted from Hauschild et al. ${ }^{31}$

\subsection{Uncertainties and limitations}

Although the assessment was performed with the best available data at the time of study, a number of uncertainties and limitations were identified. These stem from the three main components of the assessment: (1) the electricity generation data, (2) the life cycle inventories, and (3) the LCIA methods.

Historical data on electricity generated from fossil fuels were incomplete for some countries, particularly in Africa, Central and South America and Asia and Oceania, and extrapolations were therefore performed (see ESI-1, Supplementary Methods $\dagger$ ). This gap-filling procedure primarily refer to small countries and territories, e.g. islands, hence original data still retain a coverage of more than $99 \%$ of worldwide electricity from fossils (see ESI-1, Supplementary Methods $\dagger$ ). Therefore, global and regional assessments are likely not to be impacted by this uncertainty source, but national assessments may be associated with uncertainties for some countries, in particular those 
for which the extrapolated data had to be combined with unspecific life cycle inventories, i.e. LCIs for "rest of the world" -see Section 2.2. Such countries are identified in Table S2 in ESI-1†, and caution is recommended to the reader when analysing and interpreting their associated results.

The alignment between the life cycle inventories and the electricity data based on the 2008 production volumes (see Section 2.2) did not allow accounting for the evolution of the different technologies over time. For most countries, it is deemed to be of minor influence because the lifetime of power plants is generally longer than the timeline of 32 years analysed in this study. This assumption may be particularly true for large-scale power plants that have a relatively mature technology (e.g. fossils-based power plants, nuclear plants) but it may be less applicable to renewables-based power plants, for which the technological landscape is likely to have changed significantly in some countries over the past 35 years (e.g. solar and wind power technologies ${ }^{48-50}$ ). The distributions of the technologies based on the 2008 production volumes, e.g. for solar power or wind power, may therefore not be representative of the distributions in other years, and the lack of time differentiation prevented to accurately capture the possible shifts in environmental burdens of the technologies. For this reason, the results were not interpreted at the detailed level of each of these technologies, and only overall results per energy source are considered (e.g. wind power as a whole). In addition, the lack of time differentiation for the analysed technologies means that the feedback of the changing electricity mixes on the environmental performances of the power plants was not included. Unlike fossils-based power plants, which concentrate impacts during the operations of the plants, renewables may be sensitive to such exclusion as their impacts primarily stem from the manufacturing and decommissioning of the power plants. ${ }^{25}$ This would apply to countries, for which electricity mix compositions have changed significantly between 1980 and 2011, and may thus lead to underestimation or overestimation of the impacts from renewables in those countries.

With the exception of climate change, no quantification of the uncertainties associated with the LCIA methods is currently possible. ${ }^{31}$ Hauschild et al reported three levels of recommendations to distinguish the quality of the models. ${ }^{31}$ All but that of climate change were identified in need of improvements, in particular the models addressing ecotoxicity and human toxicity and those related to resource use (e.g. land use).Finally, for the regional impacts (all impact categories but climate change and non-renewable resource depletion in this study), the LCIA methods applied herein are site-generic and do not include any spatial differentiation, i.e. accounting for the source location and the environmental conditions of the surroundings. ${ }^{51}$ Several of these LCIA methods have been recognised to be globally-applicable (e.g. USEtox-based impact categories via the use of a global default continent; Rosenbaum et al. ${ }^{36}$ ), but others exclusively rely on European models, i.e. land use and eutrophication impacts. Hauschild et al. ${ }^{31}$ emphasize that, as no consensus on globally representative LCIA methods for regional impact categories currently exist, characterisation models based on sufficiently heterogeneous regions can provide an acceptable basis to determine globallyapplicable characterisation factors. However, they also point out that large variations in the characterisation factors across different regions could be expected for some impact categories, in particular for freshwater eutrophication and perhaps marine eutrophication and respiratory inorganics. ${ }^{31}$ Therefore, the absence of such spatial differentiation in the LCIA methods, which would allow more accuracy and representativeness in the regional and national assessments, calls for careful interpretation of the results at those geographical scales. Spatially-differentiated LCIA 
methods are currently under development and should be applied in such a study whenever made available (e.g. LC Impact, http://www.lc-impact.eu/; IMPACT World+, www.impactworldplus.org/).

\section{Results and discussion}

Combining the national electricity data, the life cycle inventories and the characterisation factors from the LCIA methods, impact profiles for the 10 selected impact categories could be obtained for 199 countries spanning 32 years (1980-2011). In the analysis of the results, impact scores are studied at global scale (sum of all 199 countries), regional scale (grouping of the countries into 7 regions: North America, Central and South America, Africa, Europe, Eurasia, Asia and Oceania) and national scale. Key findings are reported below.

\subsection{Environmental impacts have intensified globally over the last decade}

Table 2 indicates the global per-capita impacts resulting from the electricity generated in 2011. These numbers can be put in perspective with known global impacts caused by anthropogenic activities. Taking the value of $8.10 \mathrm{E}+3 \mathrm{~kg}-\mathrm{CO}_{2} \mathrm{eq} /($ person.year) that was calculated for all human activities for the year 2010, ${ }^{52}$ about $27 \%$ of the global impacts on climate change are therefore found to stem from electricity generation. This is in line with recent estimates reporting that the burden of electricity and heat production in the total climate footprint accounted for $25 \%{ }^{53}$ Although of high relevance, such meaningful comparisons cannot be performed for other impact categories because of discrepancies between this study's approach and the calculation methods and data sources used to determine these gauging values (see, e.g., Refs. 54-56).

Table 2. Trends and per-capita impact scores for the impacts stemming from global electricity generation for the 10 selected impact categories. ${ }^{\text {a, b }}$

\begin{tabular}{|c|c|c|c|c|c|c|}
\hline \multirow{2}{*}{ Impact category } & \multirow{2}{*}{$\begin{array}{l}\text { Per capita } \\
\text { global impact } \\
2011\end{array}$} & \multirow{2}{*}{ Unit } & \multicolumn{3}{|c|}{$\begin{array}{l}\text { Global trend (per-capita values) } \\
\text { (\%) }\end{array}$} & \multirow{2}{*}{$\begin{array}{l}\text { Global trend } \\
\text { (absolute } \\
\text { values) } \\
(\%)\end{array}$} \\
\hline & & & 1980-1990 & $1990-2000$ & $2000-2010$ & \\
\hline Climate change & $2.19 \mathrm{E}+03$ & kg- $\mathrm{CO}_{2} \mathrm{eq} /$ pers & $11 \%$ & $11 \%$ & $30 \%$ & $163 \%$ \\
\hline $\begin{array}{l}\text { Freshwater } \\
\text { eutrophication }\end{array}$ & 7.97E-01 & kg-Peq/pers & $17 \%$ & $8 \%$ & $6 \%$ & $111 \%$ \\
\hline Marine eutrophication & $2.20 \mathrm{E}+00$ & kg-Neq/pers & $11 \%$ & $11 \%$ & $32 \%$ & $172 \%$ \\
\hline Freshwater ecotoxicity & $7.45 \mathrm{E}+03$ & CTUe/pers & $16 \%$ & $8 \%$ & $12 \%$ & $130 \%$ \\
\hline $\begin{array}{l}\text { Human toxicity } \\
\text { (cancer effects) }\end{array}$ & 6.91E-05 & CTUh/pers & $18 \%$ & $8 \%$ & $8 \%$ & $121 \%$ \\
\hline $\begin{array}{l}\text { Human toxicity (non- } \\
\text { cancer effects) }\end{array}$ & 3.04E-04 & CTUh/pers & $19 \%$ & $9 \%$ & $12 \%$ & $132 \%$ \\
\hline $\begin{array}{l}\text { Ionising radiation } \\
\text { (human health) }\end{array}$ & $4.16 \mathrm{E}+02$ & $\begin{array}{l}\mathrm{kBq}- \\
\mathrm{U}_{235} \mathrm{eq} / \mathrm{pers}\end{array}$ & $104 \%$ & $8 \%$ & $-3 \%$ & $217 \%$ \\
\hline Respiratory inorganics & $2.55 \mathrm{E}+00$ & $\begin{array}{l}\text { kg- } \\
\mathrm{PM}_{2.5} \mathrm{eq} / \text { pers }\end{array}$ & $28 \%$ & $31 \%$ & $76 \%$ & $416 \%$ \\
\hline
\end{tabular}


Laurent A., Espinosa N., 2015. Environmental impacts of electricity generation at global, regional and national scales in 1980-2011: What can we learn for future energy planning? Energy and Environmental Science 8, 689-701. DOI: 10.1039/c4ee03832k

\begin{tabular}{|l|l|l|l|l|l|l|}
\hline Land use & $1.07 \mathrm{E}+03$ & kg-C/pers & $4 \%$ & $2 \%$ & $25 \%$ & $121 \%$ \\
\hline $\begin{array}{l}\text { Non-renewable } \\
\text { resource depletion }\end{array}$ & $5.37 \mathrm{E}-03$ & kg-Sbeq/pers & $39 \%$ & $7 \%$ & $17 \%$ & $180 \%$ \\
\hline
\end{tabular}

${ }^{a}$ Cells marked in grey are accelerating trends (i.e. higher percentages than in the previous decade).

${ }^{\mathrm{b}}$ Similar table for each considered region is provided in Table S1.

Table 2 and Fig. S1, which illustrate respectively the global and regional trends over the period 1980-2011 for each impact category, show that all environmental impacts have largely augmented at global scale, with increases between $+111 \%$ and $+416 \%$ between 1980 and 2011 (see last column of Table 2). At regional scale, with the exception of Eurasia, for which impacts have dropped dramatically following the Fall of Communism, all regions in the world are associated with increasing impact scores. Asia and Oceania and the Middle East are the two regions associated with the largest increases, with factors of up to 1-2 orders of magnitude between 1980 and 2011 for some impact categories (see Fig. S1 and Table S1). To discount the part of those increases stemming from the population growth, on which policy-makers can difficultly act, the impact scores were normalised by the population, thus leading to the global per-capita trends displayed in Table 2 (regional trends are also available in Table S1). It can be observed that, with the exception of ionising radiation, for which a recent decrease is observed, the impact-specific global trends are all positive, thus indicating that impacts have all increased over the period 1980-2011 for other reasons than population growth. Causes of these increases are the combined effect of an increasing average electricity demand per person in the world, primarily driven by developing economies in Asia (e.g. China) and the Middle East (e.g. Saudi Arabia), and the intensifying draw on fossil fuels, in particular coal, to absorb that increase in the demand. ${ }^{1,57}$

Although nearly all impacts had steady (e.g. climate change) or decelerating (e.g. toxic impacts) increases between 1980 and 2000, all but freshwater eutrophication, human toxicity (cancer effects) and ionising radiation gained an accelerating increase between 2000 and 2010. In particular, soaring increase rates characterise climate change, marine eutrophication, respiratory inorganics, land use and non-renewable resource depletion, thus indicating that not only environmental impacts increase globally but they increase faster than they were in the pre-2000 decade. However, this alarming global intensification of environmental impacts is not uniformly geographically-distributed and important discrepancies exist between regions -see Table S1. Asia and Oceania, and, to a much lesser degree, Eurasia and Africa (for some impact categories) are the regions associated with rising impact increase rates over the last decades while other regions are associated with decreasing rates. North America and Europe are even associated with decreasing impacts (see negative trends in Table S1). All per-capita impacts have thus decreased by ca. $-3 \%$ to $-17 \%$ in North America over the period 2000-2010, while per-capita impacts in Asia and Oceania have largely increased with rates comprised between ca. $+23 \%$ and $+134 \%$ over the same period (Table S1).

Asia and Oceania, North America and Europe are the driving regions although their contributions to global impacts differ from one impact category to another, e.g. respiratory inorganics versus freshwater ecotoxicity (see Fig. 1A). Coal-based electricity generation is largely driving the impact scores at global scale, with the exclusion of the impact category 'ionising radiation' (driven by the use of nuclear power plants, ca. 95\%) -see Fig. 1B and Fig. S2 (disaggregated distributions at regional scale). Coal-fuelled power plants are known to cause significant emissions of greenhouse 
gases and inorganics, like nitrogen oxides and heavy metals, which are important contributors to most environmental impacts. ${ }^{54,55,58,59}$ In their striving toward holistic energy planning (see Section 4), policy-makers should therefore give high priority to this issue. The IEA has already emphasized the importance of phasing-out subcritical coal-fired power plants. ${ }^{60}$ Other means could include the enforcement of more stringent emission regulations, not only focusing on greenhouse gases but also targeting other damaging substances; e.g. specific heavy metals impacting ecosystems and human health. Furthermore, because the global impacts are predominantly distributed over Asia and Oceania, Europe and North America (Fig. 1A) whereas their intensifications primarily take place in Asia and Oceania (Table S1), it can be expected that an increasing share of the global environmental burden will be placed on Asia and Oceania in the future, thus emphasizing the particular need for consistent energy planning in that region.
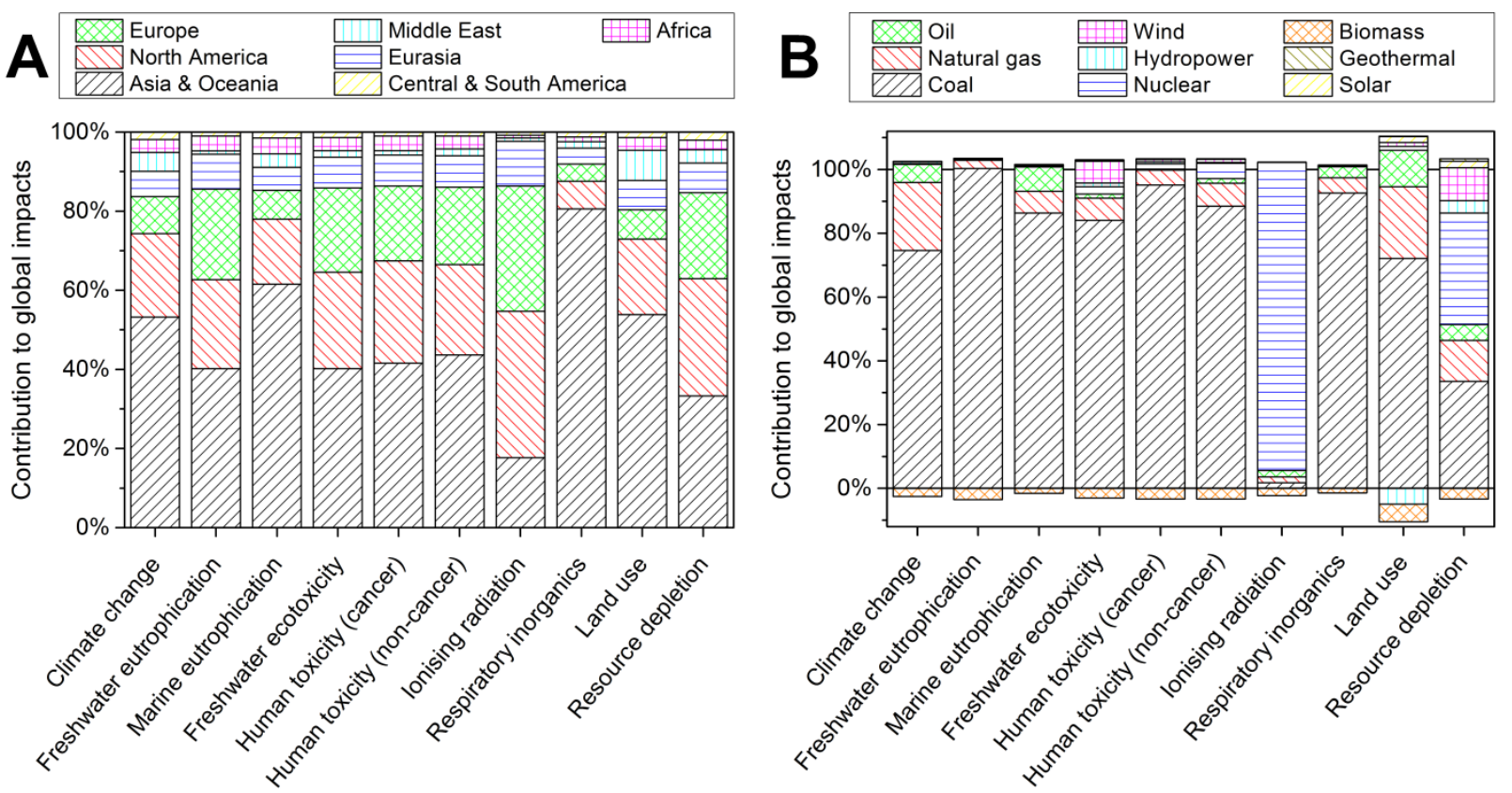

Fig. 1. Contribution of different regions (A) and energy sources (B) to global impacts in 2011.

\subsection{Environmental impact burden-shifting has occurred in the past}

Fig. 2 (and Fig. S3) shows that impact trends can vary considerably between countries for a given environmental impact category, e.g. freshwater eutrophication-related impacts in Italy increasing by a factor of ca. 4.1 over the period 1980-2011 while those in the United Kingdom being halved in the same period. Large differences can also be observed between impact categories for a given country such as climate change impacts decreasing in France by more than 60\% between 1980 and 2011 while freshwater ecotoxicity impacts increasing by more than $50 \%$ in the same period (Fig. S3). These discrepancies stem from three main causes reflecting the specificity of each individual country: (1) the electricity demand, with strong dependence on population growth, (2) the technology levels/developments of the power plants and (3) the types of energy carriers composing the electricity mixes. The relative balance between these three parameters at a given point in time determined the observed impact profiles. For example, analysing the contribution to climate change 
impacts in France between 1980 and 2011 reveals that the increasing electricity demand, which is partly influenced by population growth, has been counter-balanced by the effective switch from a fossils-based mix to a nuclear power-based mix, thus resulting in a net decrease of climate change impacts.

However, Fig. 2 illustrates that the large time variations observed across impact categories have been associated for many countries with environmental burden-shiftings, i.e. when some environmental impacts are reduced while other relevant ones increase. ${ }^{25}$ Taking on the environmental profile of France between 1980 and 2011, it can thus be observed that, while climate change impacts decrease, other environmental impacts may remain at the same level due to the necessary production and decommissioning of the facilities and the operations of the power plants, e.g. toxic impacts on human health (i.e. 'human toxicity' in Fig. 2). Similar trends can be noted for other countries, e.g. Switzerland (ca. 70\% decrease for climate change impacts while 50-75\% increase for toxicity-related impacts between 1980 and 2011) or Austria (ca. 25\% increase in climate change impacts while 65\% decrease of respiratory impacts caused by inorganics between 1980 and 2011).
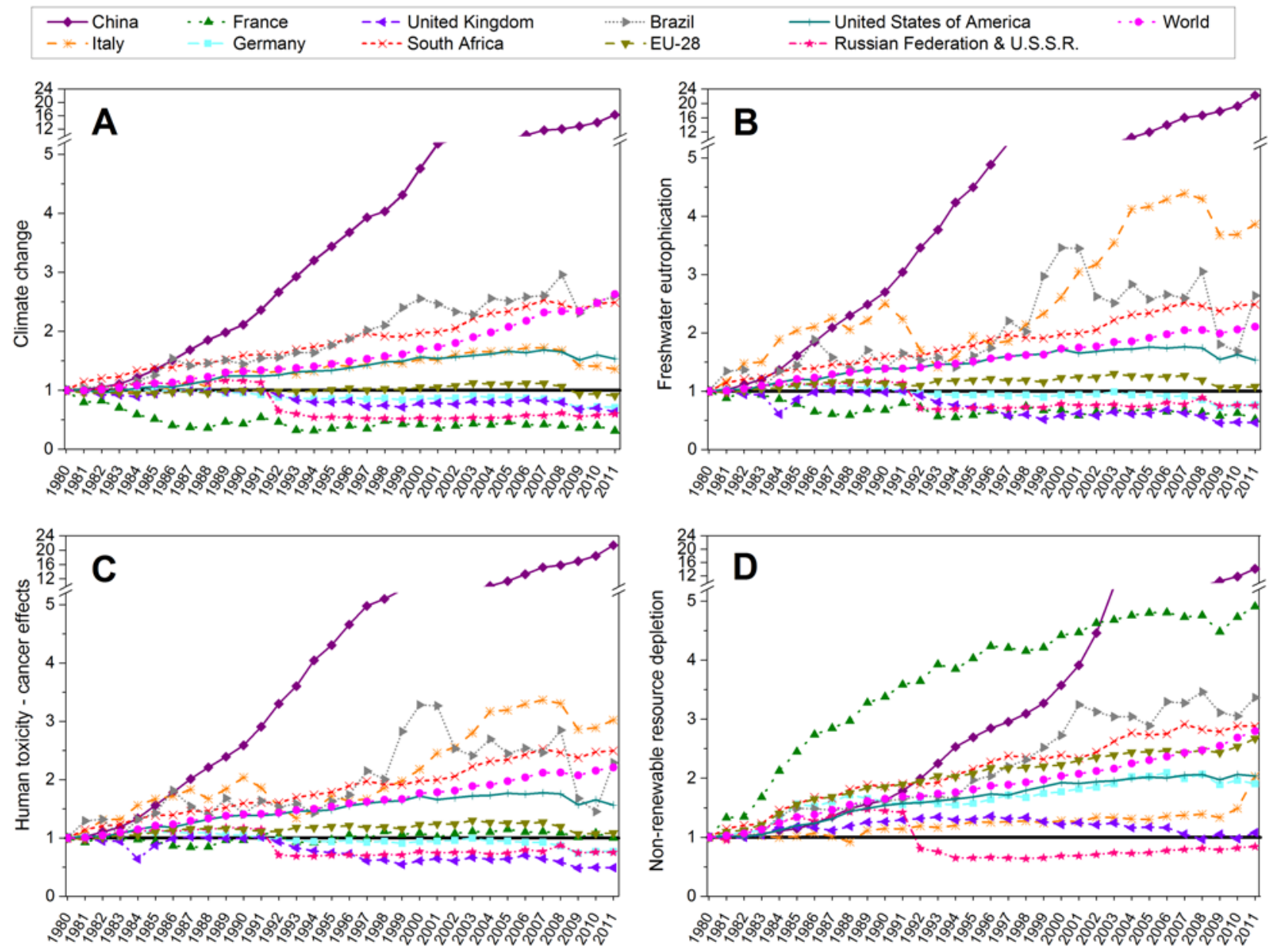

Fig. 2. Impact trends of selected countries over the period 1980-2011 for (A) climate change, (B) freshwater eutrophication, (C) carcinogenic impacts of chemicals ('human toxicity - cancereffects'), and (D) non-renewable resource depletion. Trends are calculated using impact scores in 1980 as baseline. Similar graphs for all impact categories are provided in Fig. S3. 
Laurent A., Espinosa N., 2015. Environmental impacts of electricity generation at global, regional and national scales in 1980-2011: What can we learn for future energy planning? Energy and Environmental Science 8, 689-701. DOI: 10.1039/c4ee03832k

\subsection{Two general patterns in impact trends have emerged}

To identify patterns, impact results were divided by the total electricity generated for each country in each year (see Table S4 in ESI-2†). Among the 3 major causes influencing the impact trends (Section 3.2), the electricity demand is thus discounted, which allows to investigate the influences of the technological levels and types of electricity mixes. Because the life cycle inventories used in the study were not differentiated over time (see Section 2.2 and 2.4), no changes of technological efficiency between years are included, and only differences in technological levels across countries are reflected in the results. Therefore, the results can be considered to represent the "cleanness" of each country's electricity mixes, and investigating their changes over time can provide an overview of the trends in impact intensities from a given electricity mix (in impact metrics per unit of electricity generated).

Fig. 3 shows impact intensities for selected impacts and countries. Detailed results for all countries and impact categories are also available in ESI-1† (Fig. S4) and ESI-2† (Table S4). Different rankings of countries are observed across impact categories, with differences of more than one order of magnitude between the lowest and highest impact intensities for most impact categories. This demonstrates a strong national specificity in the impact profiles, which originate from each country's electricity supply landscapes that include the type of electricity sources composing the mix and the characteristics of the technology used, such as the plant efficiencies and the emission standards.

The trends displayed in Fig. 3 and in Fig. S4 and S5 are consistent with those interpreted in Section 3.2, demonstrating that burden-shifting has occurred over the past 30 years for many countries, particularly in developed economies, where the focus on switching from fossil fuels to renewable sources has been more important. It is observed that, although climate change impacts have progressively decreased in many countries in Europe and North America as their grid integrated more renewable shares, other environmental impacts have stagnated or increased because these primarily stemmed from the manufacturing and deployment of energy systems, e.g. systems relying on renewables. In contrast, in developing economies, such as India and China, no burden-shifting can generally be observed as the majority of impacts have kept increasing since 1980 -see Fig. 3 and Fig. S5.

Therefore, although uncertainties are associated with these findings (see Section 2.4), two general patterns seem to currently co-exist in the global environmental burden caused by electricity generation. In developing economies, energy policies have not primarily or have ineffectively targeted environmental problems, thus leading to high impact intensities, i.e. “dirtier” electricity mixes. In developed economies, the effect of energy policies towards reducing climate change impacts and the use of fossils can effectively be observed (lowest intensities for climate change in Fig. 3). However, although there seem to be some correlations across impact categories (see Fig. S5), which led to co-decreases of some impact categories, other environmental impacts than climate change and fossils depletion have largely been overlooked. 


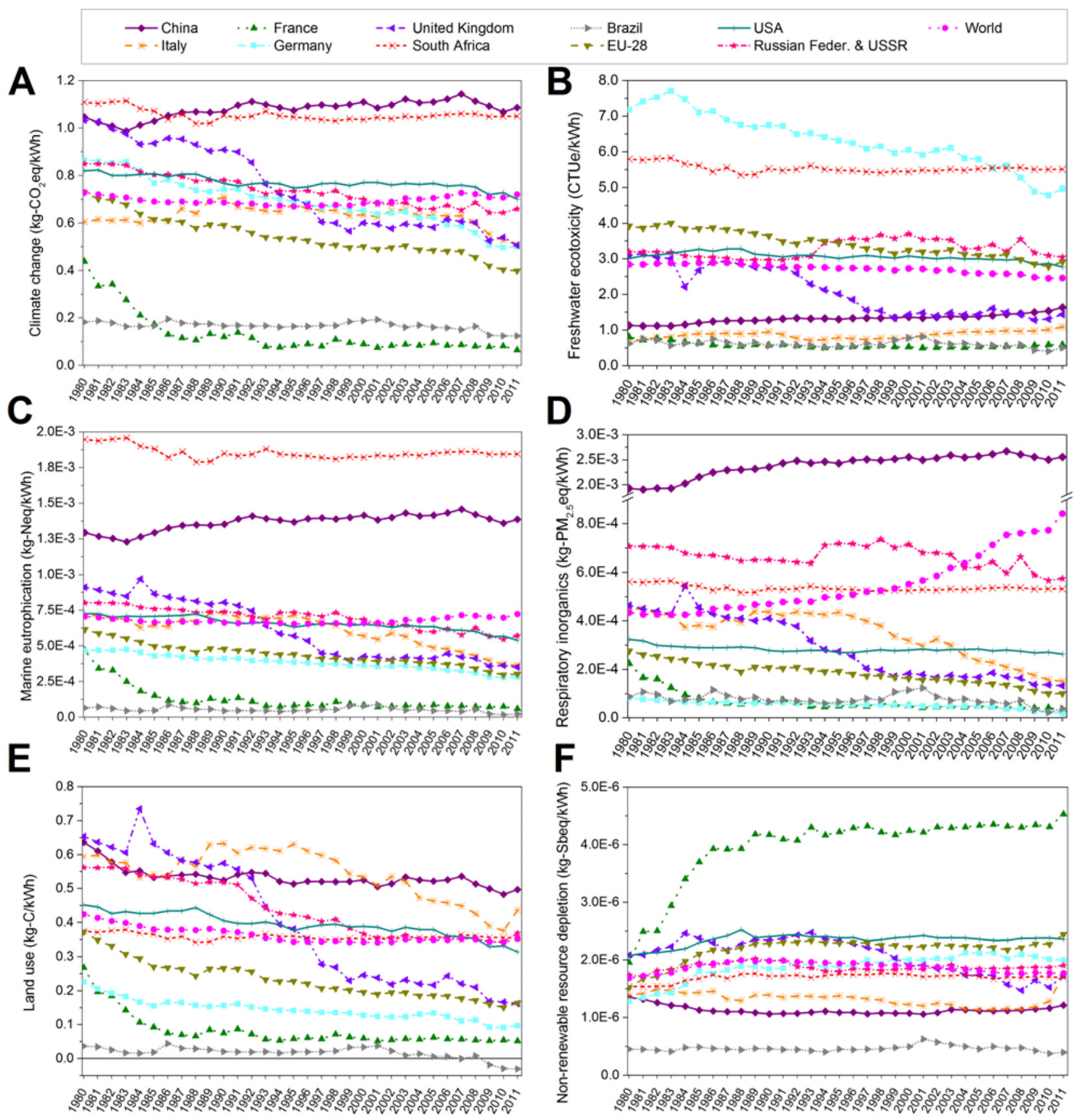

Fig. 3. Impact intensities reflecting the "cleanness" of national electricity mixes for 11 selected countries/regions and 6 impact categories: (A) climate change, (B) freshwater ecotoxicity, (C) marine eutrophication, (D) respiratory inorganics, (E) land use, and (F) non-renewable resource depletion. Impact intensities are expressed in impact-specific units per kWh of electricity generated. Results for other environmental categories are presented in Fig. S4 in ESI-1†. Trends of these impact intensities over 1980-2011 (baseline: 1980) are provided for each selected country in Fig. S5 in ESI-1†. National results are available in Table S4 in ESI-2†. 
Laurent A., Espinosa N., 2015. Environmental impacts of electricity generation at global, regional and national scales in 1980-2011: What can we learn for future energy planning? Energy and Environmental Science 8, 689-701. DOI: 10.1039/c4ee03832k

\section{Conclusions and recommendations for holistic energy planning}

\subsection{Integration of life cycle impact assessment into strategic energy planning is needed}

The retrospective assessment of the environmental impacts stemming from electricity generation at global, regional and national scales (see Section 3) revealed that (i) environmental impacts have globally intensified over the last decade, (ii) burden-shiftings have occurred in many countries between 1980 and 2011, and (iii) two major trends in environmental impacts seem to emerge following the two major trends of stable and dynamic power systems. Therefore, in the light of these past trends and the current emphasis of international and national energy policies on climate change mitigation, there is a risk that strategic electricity planning might inadvertently lead to suboptimisation, e.g. where climate change impacts would be reduced at the expenses of other environmental impacts. In addition, the large variations in environmental impacts observed between the countries indicate that the environmental profiles of electricity generation systems are far from being geographically homogeneous. It means that, although low-carbon technologies for electricity supply recently have been reported to bring environmental benefits at global scale, ${ }^{24}$ discrepancies may arise for specific countries, e.g. with the presence of environmental trade-offs. Strong dependencies on the context and specificities of each country exist, such as the mix of energy sources used, the resource availability and the type and efficiencies of the power plants.

One of the strengths of LCA resides in its ability to capture such specificities and account for them in the quantification of environmental performances of electricity systems. ${ }^{5,7}$ We therefore call for policy-makers to move towards a holistic perspective and routinely integrate life cycle impact assessment into strategic electricity planning. By nature, LCA is a systemic tool and is thus highly relevant for evaluating long-term electricity trajectories, which can encompass all electricity supply systems and their interactions with other systems and society at large.

LCA can support the elaboration of policies to meet global or regional challenges. For example, environmental goals or targets at regional level (e.g. 2020 or 2030 policy targets at the EU level) could be met by using LCA as an instrument to distribute the efforts required by each party involved depending on its energy and societal landscape. At national level, LCA could support the definition and management of energy policies, to set and control targets while ensuring that potential environmental trade-offs are identified and future burden-shifting are anticipated and prevented in time. It can also allow identifying hotspots and refining existing energy policies, e.g. supporting amendments in national emission standards and prioritizing or targeting specific energy sources and technologies identified as important causes of impacts in the countries considered.

\subsection{Normalisation as a possible tool for prioritisation}

To support the use of LCA in policy-making, "sectorial normalisation” can be used to identify key environmental indicators and target relevant impacts at regional or national level. The impact scores caused by electricity generation at global scale are taken as normalisation references. For each impact category, the impacts caused by electricity generation at regional or national scale are then compared against these references. ${ }^{61}$ To obtain results that are easier to analyse and communicate, the impact scores of both the normalisation references and the result to normalise can be divided by a key parameter that is specific to a given country and year. Below, two examples are provided with the use of population and generated electricity as key parameters, respectively. 
Tables S2 and S3 show the results of the application of normalisation to the 2011 per-capita impact scores at regional scale and national scale, respectively. Because of the discounted population growth, it therefore can be used to identify which key impacts are higher than the global average and should be prioritised within the sector of electricity production. China shows for example large per-capita impact scores for respiratory inorganics in 2011 (са. 3.3 times higher than the global average), and to a lesser extent, for marine eutrophication (ca. 2.1), climate change (ca. 1.7) and land use (ca. 1.6), all mainly caused by coal-fired plants (see also Section 3.1). Benchmarking against the global average and assuming an equal weight between impact categories, these four impacts should therefore be prioritised in electricity generation sector in China.

Normalisation using as key parameter the total electricity generated (in each country and year considered) can also provide useful support for decision-making. With the scope of the current study, such approach enables the representation of the "cleanness" of the electricity mixes (see Section 3.3). Besides giving an overview of the impact intensities (see Section 3.3), an analysis over time can (i) reveal impact trade-offs from a given electricity mix at a specific point in time, (ii) unveil potential burden-shifting that may have occurred in the past years or will occur as a result of energy policies (complementary to the analysis in Section 3.2 because of the normalisation per electricity output), and (iii) identifying hot spots on which policy-makers can focus to steer future electricity planning or electricity transition programmes towards more environmentally sustainable energy systems.

In Tables S5 and S6 in ESI-2†, such a normalisation approach is applied. The results of Table S6 are captured visually in Fig. 4, in which the observed horizontal colour changes for a given impact category symbolise that the ranking of normalised impacts has changed. Illustrating the national results for the period 1980-2011, Fig. 4 clearly indicates at a glance that environmental burdenshifting has occurred in the electricity mixes for most countries (assuming equal significance weighting across impact categories). This graphical method can also support the identification of hotspots, i.e. largest impacts, in the electricity mix of a given country in a given year that policies should target. As observed in Fig. 4, a number of impacts, such as climate change, marine eutrophication, freshwater ecotoxicity, land use and non-renewable resource use are generally associated with warm colours (dark red-yellow), indicating that they are consistently the largest environmental impacts within the global electricity generation sector. In contrast, impact categories such as ionising radiation and freshwater eutrophication are generally consistently the lowest environmental impacts within the electricity generation sector (albeit with important national variations). Similar ranking applied across countries in the world, that is in vertical direction, can also provide information to benchmark the performances of a given country compared to others for a given impact category.

However, although these normalised results give indications for policy-making on where to prioritise efforts, they do not reflect which impacts should be intrinsically prioritised because they consider the electricity generation systems in isolation, i.e. only normalising with global impacts within the electricity generation sector. The normalisation approaches proposed in the above therefore do not allow for comparing the environmental burden caused by electricity generation with the entire global, regional or national footprint caused by human activities and the respective planetary boundaries defining a "safe operating space for humanity" ${ }^{62,63}$ To date, no methodology exists to consistently make such assessment. Several research efforts currently aim at better refining 
and estimating the planetary boundaries originally defined by Rockstrom et al. ${ }^{63}$ and at developing consistent footprinting methodologies (e.g. Refs. 64, 65). When made available, this information can be expected to be a tremendous support to policy-making as they should enable to define environmentally sustainable electricity systems that would guarantee no overshoot of the global, regional or national thresholds imposed by the planetary boundaries.
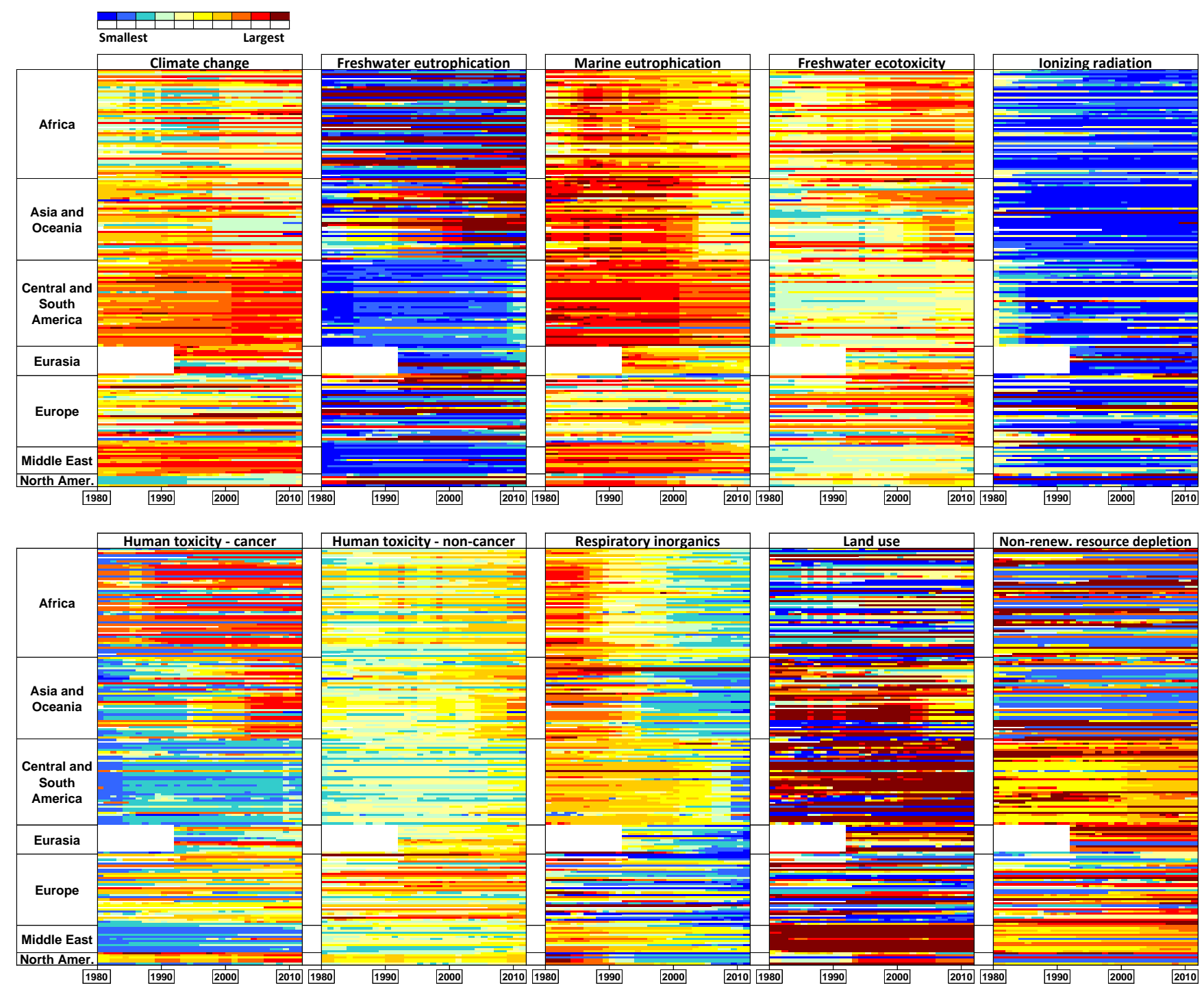

Fig. 4. Time-differentiated normalised national impact intensities (world as reference) with ratios sorted across the ten considered impact categories for each year and country (total of 199 countries and 32 years). To obtain these normalised results, per-kWh impact scores of each impact category, year and country were divided by global per-kWh impact scores (same year), thus yielding a dimensionless ratio. A colour scaling system was then applied at an individual country level for each year to rank the magnitude of the impact scores for the ten impact categories (from dark blue lowest ratio - to dark red - largest ratio). Exact values for each country, year and impact category are available in Table S6 in ESI-2†. 


\subsection{Further research needs}

The retrospective impact assessment presented in this paper offers a first attempt at providing backsight knowledge on the environmental impacts of electricity generation systems, on which policy-makers and stakeholders in the field of electricity sector can draw to establish and steer strategic electricity plans towards more environmental sustainability. Although it was conducted using recommended LCIA methods and the most advanced and detailed data available at the time of the study (LCI and historical data), methodological uncertainties and limitations could be noted (see Section 2.4). Therefore, in addition to the recommendations provided to energy policy makers in Section 4.1-4.2, we emphasize below a number of specific methodological developments directed to improving the reliability of the LCA results and the subsequent support for policy-making:

- Development of a consistent framework for performing foresight studies, i.e. accounting for the environmental performances of future technologies once deployed on the market (incl. upscaling effects for emerging technologies) and allowing for integrating anticipated impacts into decision- and policy-making processes. Such framework should accommodate the dynamics of the different systems in a short-term, medium-term and long-term perspective, together with a comprehensive impact assessment module. The use of hybrid approaches, combining process-based LCA (i.e. as performed in this study) with input-output tables, as the ones proposed by Hertwich et al. ${ }^{24}$ or Wiedmann et al. ${ }^{66}$ can be relevant alternatives for that purpose.

- Adoption of a systemic perspective as holistic as possible in the modelling of the energy systems. The dynamics of all systems impacted and impacting electricity systems should be integrated, including their mutual interactions via different technical, economical and societal mechanisms, e.g. efficiency gains, market effects, human behaviour, etc. (e.g. see review of energy system modelling in Pfenninger et al. ${ }^{67}$ ). Such perspective is a necessary condition to prevent impact burden-shifting from one system to another to happen, and should be realised by the developed framework (see first bullet point).

- Generation of multi-scale data for electricity systems. Spatially-differentiated data about the characteristics of the systems (e.g. efficiencies, types of technology, etc.) as well as the associated resource consumption and pollutant emission factors (including all pollutants emitted to air, water and soil) are needed for individual countries or regions. In the context of foresight studies, it is necessary to differentiate these data over time (e.g. via use of forecasting or normative scenarios). Section 2.2 and Supplementary Methods in ESI-1† provide an overview of the current state of life cycle inventories of power plants, still reflecting important data gaps for many countries in the world. To our knowledge, no time differentiation is currently embedded in available life cycle inventories.

- Development of spatially-differentiated LCIA methods that can match the level of details of the inventory in terms of location of the emission sources. Wherever relevant, a dynamic perspective should also be included, e.g. for assessing contributions to climate change. ${ }^{68-71}$

- Integration of environmental, economic and social sustainability assessments to cover all aspects of sustainability. Strong research needs still reside in the development of methodologies for assessing economic and social sustainability. ${ }^{72-75}$ 
- Definition and development of consistent planetary boundaries and environmental footprinting methods for use in decision support to identify environmentally sustainable energy systems (see Section 4.1).

\section{Notes and References}

$\dagger$ Electronic Supplementary Information (ESI) available: ESI-1 containing Supplementary Methods and Supplementary Results and Discussions (Figs. S1-S5; Tables S1-S3). ESI-2 containing Supplementary Results (Tables S4-S6).

1 IEA, World Energy Outlook 2013, International Energy Agency, Paris, FR, 2013.

2 United Nations, Kyoto Protocol to the United Nations Framework Convention on Climate Change (UNFCCC). United Nations, Paris, FR, 1998.

3 The Danish Government, 2013, The Danish Climate Policy Plan Towards a Low Carbon Society, 2013, $\quad$ http://www.ens.dk/sites/ens.dk/files/policy/danish-climate-energypolicy/danishclimatepolicyplan_uk.pdf (Accessed on 16/11/2014).

4 European Commission, 2030 Framework for Climate and Energy - Outcome of the October 2014 European Council, 2014, http://ec.europa.eu/clima/policies/2030/documentation_en.htm (Accessed on 16/11/2014).

5 S. Hellweg and L. Milà i canals, Science, 2014, 344, 1109-1113.

6 E. Masanet, Y. Chang, A. R. Gopal, P. Larsen, W. R. Morrow, R. Sathre, A. Shehabi and P. Zhai, Annu. Rev. Environ. Resour., 2013, 38, 107-136.

7 M. Z. Hauschild, Environ. Sci. Technol., 2005, 39, 81A-88A.

8 M. Whitaker, G. A. Heath, P. O'Donoughue and M. Vorum, J. Ind. Ecol., 2012, 16, S53-S72.

9 A. Arvesen and E. G. Hertwich, Renew. Sust. Energ. Rev., 2012, 16, 5994-6006.

10 M. Caduff, M. A. J. Huijbregts, H. J. Althaus, A. Koehler and S. Hellweg, Environ. Sci. Technol., 2012, 46, 4725-4733.

11 S. L. Dolan and G. A. Heath, J. Ind. Ecol., 2012, 16, S136-S154.

12 P. Padey, R. Girard, D. le Boulch and I. Blanc, Environ. Sci. Technol., 2013, 47, 201231-1238.

13 H. L. Raadal, L. Gagnon, I. S. Modahl and O. J. Hanssen, Renew. Sust. Energ. Rev., 2011, 15, 3417-3422.

14 N. Espinosa, R. Garcia-Valverde, A. Urbina and F. C. Krebs, Sol. Energ. Mat. Sol. C., 2011, 95, 1293-1302.

15 J. J. Burkhardt, G. Heath and E. Cohen, J. Ind. Ecol., 2012, 16, S93-S109.

16 D. D. Hsu, P. O'Donoughue, V. Fthenakis, G. A. Heath, H. C. Kim, P. Sawyer, J. K. Choi and D. E. Turney, J. Ind. Ecol., 2012, 16, S122-S135.

17 J. Peng, L. Lu and H. Yang, Renew. Sust. Energ. Rev., 2013, 19, 255-274. 
Laurent A., Espinosa N., 2015. Environmental impacts of electricity generation at global, regional and national scales in 1980-2011: What can we learn for future energy planning? Energy and Environmental Science 8, 689-701. DOI: 10.1039/c4ee03832k

18 P. Viebahn, Y. Lechon and F. Trieb, Energ. Policy, 2011, 39, 4420-4430.

19 M. Pehnt, Renew. Energ., 2006, 31, 55-71.

20 K. Treyer, C. Bauer and A. Simons, Energ. Policy, 2014, 74, S31-S44.

21 Varun, I. K. Bhat and R. Prakash, Renew. Sust. Energ. Rev., 2009, 13, 1067-1073.

22 S. Roth, S. Hirschberg, C. Bauer, P. Burgherr, R. Dones, T. Heck and W. Schenler, Ann. Nucl. Energy, 2009, 36, 409-416.

23 H. Lund, B. V. Mathiesen, P. Christensen and J. H. Schmidt, Int. J. Life Cycle Assess., 2010, 15, 259-271.

24 E. G. Hertwich, T. Gibon, E. A. Bouman, A. Arvesen, S. Suh, G. A. Heath, J. D. Bergesen, A. Ramirez, M. I. Vega and L. Shi, Proc. Natl. Acad. Sci. U. S. A., 2014, DOI: 10.1073/pnas.1312753111.

25 A. Laurent, S. I. Olsen and M. Z. Hauschild, Environ. Sci. Technol., 2012, 46, 4100-4108.

26 Data Shift Project, Electricity Generation Statistics, http://www.tsp-data-portal.org/Breakdownof-Electricity-Generation-by-Energy-Source\#tspQvChart (Accessed 20/3/2014), 2014.

27 World Bank database, Electricity production figures, http://data.worldbank.org/ (Accessed 20/3/2014), 2014.

28 B. P. Weidema, C. Bauer, R. Hischier, C. Mutel, T. Nemecek, J. Reinhard, C. O. Vadenbo, G. Wernet, Overview and methodology. Data quality guideline for the ecoinvent database version 3. Ecoinvent Report 1(v3). The ecoinvent Centre, St. Gallen, CH, 2013.

29 K. Treyer and C. Bauer, Int. J. Life Cycle Assess., 2013, DOI 10.1007/s11367-013-0665-2.

30 K. Treyer and C. Bauer, Int. J. Life Cycle Assess., 2013, DOI 10.1007/s11367-013-0694-X.

31 M. Z. Hauschild, M. Goedkoop, J. Guinée, R. Heijungs, M. A. J. Huijbregts, O. Jolliet, M. Margni, A. De Schryver, S. Humbert, A. Laurent, S. Sala and R. Pant, Int. J. Life Cycle Assess., 2013, 18, 683-697.

32 European Commission (EC) - Joint Research Centre - Institute for Environment and Sustainability, International Reference Life Cycle Data System (ILCD) Handbook Recommendations for Life Cycle Impact Assessment in the European context. First edition November 2011. EUR 24571 EN. Publications Office of the European Union, Luxembourg, LU, 2011.

33 E. Moreno Ruiz, T. Lévová, G. Bourgault and G. Wernet, Documentation of changes implemented in ecoinvent Data 3.1. ecoinvent, Zurich, CH, 2014.

34 Intergovernmental Panel on Climate Change (IPCC), Climate Change 2007: The Physical Science Basis. Contribution of Working Group I to the Fourth Assessment Report of the Intergovernmental Panel on Climate Change, Cambridge University Press, Cambridge, United Kingdom and New York, NY, USA, 2007.

35 J. Struijs, A. Beusen, H. van Jaarsveld and M. A. J. Huijbregts, Aquatic eutrophication. Chapter 6. In: M. Goedkoop, R. Heijungs, M. A. J. Huijbregts, A. De Schryver, J. Struijs, R. van Zelm, ReCiPe 2008 - A life cycle impact assessment method which comprises harmonised category 
indicators at the midpoint and the endpoint level. Report I: characterisation, version 1.08 (May 2013), http://www.lcia-recipe.net (Accessed 11 January 2015). Ministry of Housing, Spatial Planning and the Environment, NL, 2009.

36 R. K. Rosenbaum, T. M. Bachmann, L. S. Gold, M. A. J. Huijbregts, O. Jolliet, R. Juraske, A. Koehler, H. F. Larsen, M. MacLeod, M. Margni, T. E. McKone, J. Payet, M. Schuhmacher, D. van De Meent and M. Z. Hauschild, Int. J. Life Cycle Assess., 2008, 13, 532-546.

37 A. D. Henderson, M. Z. Hauschild, D. van De Meent, M. A. J. Huijbregts, H. F. Larsen, M. Margni, T. E. McKone, J. Payet, R. K. Rosenbaum and O. Jolliet, Int. J. Life Cycle Assess., 2011, 16, 701-709.

38 R. K. Rosenbaum, M. A. J. Huijbregts, A. D. Henderson, M. Margni, T. E. McKone, D. van De Meent, M. Z. Hauschild, S. Shaked, D. S. Li, L. S. Gold and O. Jolliet, Int. J. Life Cycle Assess., 2011, 16, 710-727.

39 M. Dreicer M, V. Tort V and P. Manen, ExternE, externalities of energy, vol. 59 Nuclear. Centre d'étude sur l'Évaluation de la Protection dans le domaine 10 nucléaire (CEPN). In: European Commission DGXII (ed) Science, 11 Research and development JOULE, Luxembourg, LU, 1995.

40 R. Frischknecht, A. Braunschweig, P. Hofstetter and P. Suter, Environ. Impact Assess. Rev., 2000, 20, 159-189.

41 M. Goedkoop, R. Heijungs, M. A. J. Huijbregts, A. De Schryver, J. Struijs and R. van Zelm, (2013), ReCiPe 2008 - A life cycle impact assessment method which comprises harmonised category indicators at the midpoint and the endpoint level. Report I: characterisation, version 1.08 (May 2013), http://www.lcia-recipe.net (Accessed 11 January 2015). Ministry of Housing, Spatial Planning and the Environment, NL, 2009.

42 S. Humbert, Geographically Differentiated Life-Cycle Impact Assessment of Human Health, Ph.D. Dissertation. AAT 3402614, University of California, Berkeley, USA, 2009.

43 A. Rabl and J. Spadaro, 2004, The RiskPoll software, version 1.051 (dated August 2004). www.arirabl.com (Accessed January 2015).

44 S. L. Greco, A. M. Wilson, J. D. Spengler and J. I. Levy, Atmos. Environ., 2007, 41, 1011-1025.

45 L. Milà i Canals, S. J. Cowell and J. Romanyà, J. Clean. Prod., 2007, 15, 1426-1440.

46 J. B. Guinée, M. Gorrée, R. Heijungs, G. Huppes, R. Kleijn, A. d. Koning, L. v. Oers, A. Wegener Sleeswijk, S. Suh, H. A. Udo de Haes, H. d. Bruijn, R. v. Duin and M. A. J. Huijbregts, Handbook on life cycle assessment. Operational guide to the ISO standards. I: LCA in perspective. IIa: Guide. IIb: Operational annex. III: Scientific background, Kluwer Academic Publishers, Dordrecht, NL, 2002.

47 L. van Oers, A. de Koning, J.B. Guinée and G. Huppes, Abiotic resource depletion in LCA Improving characterisation factors for abiotic resource depletion as recommended in the new Dutch LCA Handbook. Accessed in January 2015 at: http://www.cml.leiden.edu/research/industrialecology/researchprojects/finished/abioticdepletion-lcia.html. DWW report, Delft, NL, 2002. 
Laurent A., Espinosa N., 2015. Environmental impacts of electricity generation at global, regional and national scales in 1980-2011: What can we learn for future energy planning? Energy and Environmental Science 8, 689-701. DOI: 10.1039/c4ee03832k

48 J. K. Kaldellis and D. Zafirakis, Renew. Energ., 2011, 36, 1887-1901.

49 F. C. Krebs, N. Espinosa, M. Hosel, R. R. Sondergaard and M. Jorgensen, Adv. Mater., 2014, 26, 29-39.

50 G. K. Singh, Energ., 2013, 53, 1-13.

51 J. Potting and M. Z. Hauschild, Int. J. Life Cycle Assess., 2006, S1, 11-13.

52 A. Laurent, M. Z. Hauschild, L. Golsteijn, M. Simas, J. Fontes, R. Wood, Normalisation factors for environmental, economic and socio-economic indicators. Deliverable 5.2. EU-FP7 PROSUITE Project, Development and application of a standardized methodology for the PROspective SUstaInability assessment of Technologies, Proj. No. 227078 FP7-ENV-2008-1, 2013.

53 IPCC, Climate Change 2014: Mitigation of Climate Change. Contribution of Working Group III to the Fifth Assessment Report of the Intergovernmental Panel on Climate Change [Edenhofer, O., R. Pichs-Madruga, Y. Sokona, E. Farahani, S. Kadner, K. Seyboth, A. Adler, I. Baum, S. Brunner, P. Eickemeier, B. Kriemann, J. Savolainen, S. Schlömer, C. von Stechow, T. Zwickel and J.C. Minx (eds.)]. Cambridge University Press, Cambridge, UK and New York, NY, USA, 2014.

54 A. W. Sleeswijk, M. A. J. Huijbregts, L. F. C. M. van Oers, J. B. Guinée and J. Struijs, Sci. Total Environ., 2008, 390, 227-240.

55 A. Laurent, A. Lautier, R. K. Rosenbaum, S. I. Olsen and M. Z. Hauschild, Int. J. Life Cycle Assess., 2011, 16, 728-738.

56 S. Cucurachi, S. Sala, A. Laurent and R. Heijungs, Environ. Sci. Technol., 2014, 48, 5674-5682.

57 IEA, Tracking Clean Energy Progress 2014, International Energy Agency, Paris, FR, 2014.

58 M. S. Reddy, S. B. Basha, H. V. Joshi and B. Jha, J. Hazard Mater., 2005, 123, 242-249.

59 Y. Zhao, S. Wang, L. Duan, Y. Lei, P. Cao and J. Hao, Atmos. Environ., 2008, 42, 8442-8452.

60 IEA, Technology Roadmap - High-Efficiency, Low-Emissions Coal-Fired Power Generation, International Energy Agency, Paris, FR, 2012.

61 A. Laurent and M. Z. Hauschild, Normalisation in LCA (Chapter 14). In: LCA Compendium The Complete World of Life Cycle Assessment (Series Eds. Klöpffer W, Curran MA), Life Cycle Impact Assessment (Eds. Hauschild M, Huijbregts M.). Springer, Dordrecht, NL, 2014.

62 J. Rockstrom, W. Steffen, K. Noone, A. Persson, F. S. Chapin, E. Lambin, T. M. Lenton, M. Scheffer, C. Folke, H. J. Schellnhuber, B. Nykvist, C. A. de Wit, T. Hughes, d. L. van, H. Rodhe, S. Sorlin, P. K. Snyder, R. Costanza, U. Svedin, M. Falkenmark, L. Karlberg, R. W. Corell, V. J. Fabry, J. Hansen, B. Walker, D. Liverman, K. Richardson, P. Crutzen and J. Foley, Ecol. Soc., 2009, 14(2):32.

63 J. Rockstrom, W. Steffen, K. Noone, A. Persson, F. S. Chapin, E. F. Lambin, T. M. Lenton, M. Scheffer, C. Folke, H. J. Schellnhuber, B. Nykvist, C. de Wit A., T. Hughes, d. L. van, H. Rodhe, S. Sorlin, P. K. Snyder, R. Costanza, U. Svedin, M. Falkenmark, L. Karlberg, R. W. Corell, V. J. Fabry, J. Hansen, B. Walker, D. Liverman, K. Richardson, P. Crutzen and J. A. Foley, Nature, 2009, 461, 472-475. 
64 G. M. Mace, B. Reyers, R. Alkemade, R. Biggs, F. S. Chapin, S. E. Cornell, S. Diaz, S. Jennings, P. Leadley, P. J. Mumby, A. Purvis, R. J. Scholes, A. W. R. Seddon, M. Solan, W. Steffen and G. Woodward, Global Environ. Chang., 2014, 28, 289-297.

65 L. Posthuma, A. Bjørn, M. C. Zijp, M. Birkved, M. L. Diamond, M. Z. Hauschild, M. A. J. Huijbregts, C. Mulder and d. M. Van, Environ. Sci. Technol., 2014, 48, 6057-6059.

66 T. O. Wiedmann, S. Suh, K. Feng, M. Lenzen, A. Acquaye, K. Scott and J. R. Barrett, Environ. Sci. Technol., 2011, 45, 5900-5907.

67 S. Pfenninger, A. Hawkes and J. Keirstead, Renew. Sust. Energ. Rev., 2014, 33, 74-86.

68 A. Levasseur, P. Lesage, M. Margni, L. Deschenes and R. Samson, Environ. Sci. Technol., 2010, 44, 3169-3174.

69 A. Levasseur, M. Brandao, P. Lesage, M. Margni, D. Pennington, R. Clift and R. Samson, Nat. Clim. Change, 2012, 2, 6-8.

70 A. Pinsonnault, P. Lesage, A. Levasseur and R. Samson, Int. J. Life Cycle Assess., 2014, 19, 1843-1853.

71 S. V. Jørgensen, M. Z. Hauschild and P. H. Nielsen, Int. J. Life Cycle Assess., 2014, 19, 919930.

72 A. Zamagni, H. Pesonen and T. Swarr, Int. J. Life Cycle Assess., 2013, 18, 1637-1641.

73 S. Sala, F. Farioli and A. Zamagni, Int. J. Life Cycle Assess., 2013, 18, 1653-1672.

74 S. Sala, F. Farioli and A. Zamagni, Int. J. Life Cycle Assess., 2013, 18, 1686-1697.

75 A. Jørgensen, I. T. Herrmann and A. Bjørn, Int. J. Life Cycle Assess., 2013, 18, 1440-1449. 